\title{
Bacterial Contamination of Dialysing Fluid of Artificial Kidney
}

\author{
ELIZABETH E. KIDD,* B.SC.
}

During haemodialysis with the Kolff twin-coil artificial kidney the patient's blood is passed through "cellophane" tubing which is immersed in a dialysing bath. This holds 100 litres of fluid, with an electrolytic composition similar to that of the normal plasma, with an addition of $0.88 \%$ glucose. During haemodialysis, urea and other nitrogenous substances appear in increasing quantities. The bath is kept at a constant temperature of $37^{\circ} \mathrm{C}$. and it was formerly our practice to change the dialysing fluid every three hours. (In the light of experience, however, we now change the bath at much shorter intervals.)

In our early endeavours with this equipment we were disturbed to note an increasing turbidity of the fluid in the bath as dialysis progressed. Knowing that the contents of the dialysing bath constituted an ideal culture medium for some bacterial species, we suspected that the turbidity might be the result of bacterial growth.

This led us to make a bacteriological investigation of the contents of the bath. The result of this we are now presenting.

The equipment had been in clinical use for approximately two years at the time this inquiry was instituted, and it was customary to subject the equipment only to routine cleaning with soap, detergents, or mild abrasives.

\section{Bacterial Contamination of Dialysing Fluid}

\section{Methods}

During dialysis $1-\mathrm{ml}$. samples of the dialysing fluid were examined bacteriologically by means of a viable count using a technique similar to that described by Miles et al. (1938). After incubation at $37^{\circ} \mathrm{C}$. for 24 hours at least three drops of a suitable dilution on nutrient agar were used to calculate the number of organisms.

Moistened swabs were employed to examine various parts of the dialysing bath and reservoir tank in which the second and third changes of solution were prepared. These swabs were taken after the tank had been cleaned and were plated on nutrient agar and incubated at $37^{\circ} \mathrm{C}$. for 24 hours.

\section{Results}

A typical result of the viable counts during a dialysis is shown in Fig. 1. The total count plotted against the time of sampling showed two precipitous falls corresponding to the times when the bath fluid was changed. During the changing of the bath the whole contents cannot be removed by the pump, so that each new bath is necessarily inoculated from its predecessor. Since there were 60,000 organisms per $\mathrm{ml}$. in the first bath of a dialysis it was also evident that this initial preparation was contaminated.

The same four bacterial species were identified in the bath fluid at the beginning of each dialysis examined. They were Pseudomonas pyocyanea, Escherichia coli, Pseudomonas stutzeri, and Achromobacter species (sp.). As the dialysis proceeded Ps. pyocyanea and Achromobacter sp. multiplied far more rapidly than the other two organisms; at the end of a dialysis there were usually about $10^{7}$ Achromobacter sp. and $10^{6}$
Ps. pyocyanea per ml. and neither of the other two organisms was isolated.

Cultures of the swabs taken from the metallic surface of the dialysing bath following the routine cleaning procedure revealed a scanty growth of each of the four organisms found in the dialysing fluid. However, swabs taken from the plastic tubing connecting the bath with the drainage and circulating pumps revealed many of each of the four organisms.

None of these organisms were obtained from the reservoir tank used to make up the second and third batches of solution.

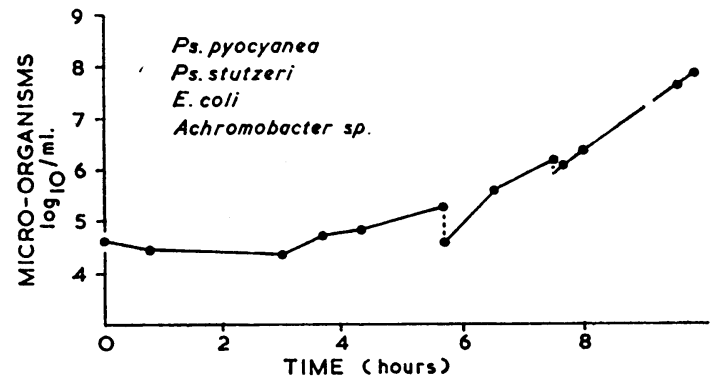

FIG. 1.- Result of viable counts made during a dialysis. The bath received no disinfectant treatment during dialyses. The sudden lowering of the viable count corresponds with the changes of fluid during the dialysis.

As unsterile tap-water, passing through the same tubing, was used to make up all batches of solution, including the two prepared in the reservoir tank, the tap-water was excluded as the source of the contamination. The dialysing tank itself was therefore regarded as the source of the contamination.

\section{Effect of Bacteria on Composition of Dialysing Fluid}

\section{Methods}

After two hours' use of three 100-litre preparations of dialysing fluid, six 400-ml. samples from each of two batches and two $400-\mathrm{ml}$. samples from the third batch were incubated at $37^{\circ}$ C. for 20 hours. As controls a filtered preparation containing urea but no organisms, and a freshly prepared medium of similar composition to the dialysing fluid which had not been dialysed against a patient, were selected. To 1 litre of this latter solution $20 \mathrm{mg}$. of urea per $100 \mathrm{ml}$. was added and to another litre $50 \mathrm{mg}$. of urea per $100 \mathrm{ml}$. A total of 4 litres of this synthetic bath were inoculated with a concentration of organisms similar to those found in the normal dialysing fluid.

Viable counts, urea and glucose estimations, and $\mathrm{Na}^{+}, \mathrm{K}^{+}$, $\mathrm{Cl}^{-}$, and $\mathrm{HCO}_{3}^{-}$concentrations were determined at the beginning and end of the incubation period.

\section{Results}

Typical results obtained from this investigation are shown in the Table. The growth of bacteria was found to produce a lowering of the urea and glucose concentrations, but there was no alteration in the $\mathrm{Na}^{+}, \mathrm{K}^{+}, \mathrm{Cl}^{-}$, and $\mathrm{HCO}_{3}^{-}$except in one instance where the bicarbonate was reduced from 29 to 
$21 \mathrm{mEq} / \mathrm{l}$. The synthetic medium was not able to support any marked growth of the bacteria unless urea was added, and even then the growth was poor compared with that in the solutions obtained after dialyses against a patient.

Effect of Bacterial Growth on Composition of the Dialysing Fluid

\begin{tabular}{|c|c|c|c|c|c|c|c|c|}
\hline \multirow{3}{*}{$\begin{array}{l}\text { Type of } \\
\text { Fluid }\end{array}$} & \multirow{3}{*}{$\begin{array}{c}\text { Time of } \\
\text { Sampling } \\
\text { (Hours) }\end{array}$} & \multicolumn{6}{|c|}{ Composition } & \multirow{3}{*}{$\begin{array}{c}\text { Viable } \\
\text { Counts } \\
\text { (orgs. } / \mathrm{ml} . \text { ) }\end{array}$} \\
\hline & & $\mathrm{Na}^{+}$ & $\mathrm{K}^{+}$ & $\mathrm{Cl}^{-}$ & $\mathrm{HCO}_{3}$ & Urea & Glucose & \\
\hline & & \multicolumn{3}{|c|}{$\mathrm{mEq} / 1$. } & \multicolumn{3}{|c|}{$\mathrm{mg} . / 100 \mathrm{ml}}$. & \\
\hline $\begin{array}{c}\text { Dialysis fluid } \\
\text { after use }\end{array}\{$ & $\begin{array}{r}0 \\
20\end{array}$ & $\begin{array}{l}134 \\
136\end{array}$ & $\begin{array}{l}5 \cdot 4 \\
5 \cdot 4\end{array}$ & $\begin{array}{l}102 \\
107\end{array}$ & $\begin{array}{l}29 \\
30\end{array}$ & $\begin{array}{l}50 \\
35\end{array}$ & $\begin{array}{l}820 \\
692\end{array}$ & $\begin{array}{l}4.5 \times 10^{5} \\
1.7 \times 10^{9}\end{array}$ \\
\hline $\begin{array}{l}\text { Sterile dialysis } \\
\quad \text { luid after use }\end{array}$ & $\begin{array}{r}0 \\
20\end{array}$ & $\begin{array}{l}134 \\
138\end{array}$ & $\begin{array}{l}4 \cdot 5 \\
4 \cdot 6\end{array}$ & $\begin{array}{l}103 \\
105\end{array}$ & $\begin{array}{l}33 \\
34\end{array}$ & $\begin{array}{l}50 \\
52\end{array}$ & $\begin{array}{l}800 \\
780\end{array}$ & $\begin{array}{l}0 \\
0\end{array}$ \\
\hline \multirow{2}{*}{$\begin{array}{l}\text { Unused dialysis } \\
\text { fluid plus } \\
\text { urea }\end{array}$} & 0 & 130 & $5 \cdot 2$ & 112 & 34 & 20 & 750 & $7.5 \times 10^{4}$ \\
\hline & 20 & 146 & $5 \cdot 2$ & 113 & 34 & 10 & 740 & $5 \times 10^{8}$ \\
\hline \multirow{2}{*}{$\begin{array}{l}\text { Unused dialysis } \\
\text { fluid without } \\
\text { urea }\end{array}$} & 0 & 130 & $5 \cdot 2$ & 112 & 34 & 0 & 750 & $9 \times 10^{4}$ \\
\hline & 20 & 140 & $5 \cdot 3$ & 114 & 34 & 0 & 720 & $8 \times 10^{4}$ \\
\hline
\end{tabular}

\section{Passage of Bacterial Substances Across the Cellophane Membrane}

\section{Cultures of Blood During Haemodialysis}

\section{Methods}

Blood cultures were prepared from samples collected at the end of 120 dialyses and in many instances from two other samples collected during the dialysis. Five millilitres of blood was removed from the external circuit, usually after the blood had passed through the coil, but 10 samples were taken before the blood entered the coil.

Three millilitres of the blood was inoculated into $40 \mathrm{ml}$. of Hartley's tryptic broth, $1 \mathrm{ml}$. to Wright's glucose broth, and $1 \mathrm{ml}$. to Colebrook's cooked-meat medium. These were incubated aerobically at $37^{\circ} \mathrm{C}$. and examined for growth at $1,2,7$, and 14 days

\section{Results}

Four patients with septicaemia were submitted to haemodialysis and in all of them the responsible organism was found in each culture made during these dialyses. However, from the 300 blood cultures made on 52 patients with initially sterile blood during 116 dialyses there was no evidence that bacteria from the dialysing bath passed into the patients' blood-stream. There was no difference in the results of 10 cultures made before and after the blood passed through the coil.

\section{Methods}

\section{In-vitro Investigations}

Tubular cellophane used in making the coils for dialysis was cut into $30-$ to $40-\mathrm{cm}$. lengths. The two ends were attached to polyvinyl tubing of a size which could be adjusted to a hypodermic syringe nozzle. Both ends were plugged with cottonwool, and these bags were then sealed in plastic bags and sterilized by gamma-irradiation. Fig. 2 shows the bag immersed in a test system to be described. The passage of various substances, selected for their ease of detection, was determined as described below, using the prepared cellophane bags.

(a) Pyocyanin.-A culture containing visible pyocyanin was prepared by incubation of Ps. pyocyanea in $100 \mathrm{ml}$. of Hartley's tryptic broth at $37^{\circ} \mathrm{C}$. for 24 hours. A sterilized bag was immersed in the culture and $10 \mathrm{ml}$. of sterile Hartley's tryptic broth, diluted $1 / 5$ in sterile water, was introduced by a syringe into the bag. After four hours' incubation at $37^{\circ} \mathrm{C}$. the inside fluid was removed by suction from a syringe and examined for pyocyanin by extraction with chloroform, the presence of pyocyanin in the chloroform fraction giving a blue-green colour

(b) Staphylococcus Aureus Haemolysin.-A preparation of Staph. aureus toxin, which haemolysed a $5 \%$ suspension of washed rabbit red blood cells at a dilution of $1 / 200$ in five minutes and at $1 / 2,000$ in five hours, was selected. Samples of undiluted toxin and a $1 / 2$ dilution were placed inside the test bags and were immersed in $100 \mathrm{ml}$. of saline and the system. left at room temperature for two days. Controls containing only saline within the bag were also prepared. The presence of the haemolysin was detected visually after the outside saline solution was incubated at $37^{\circ} \mathrm{C}$. for 18 hours with an equal volume of $5 \%$ washed rabbit red cells.

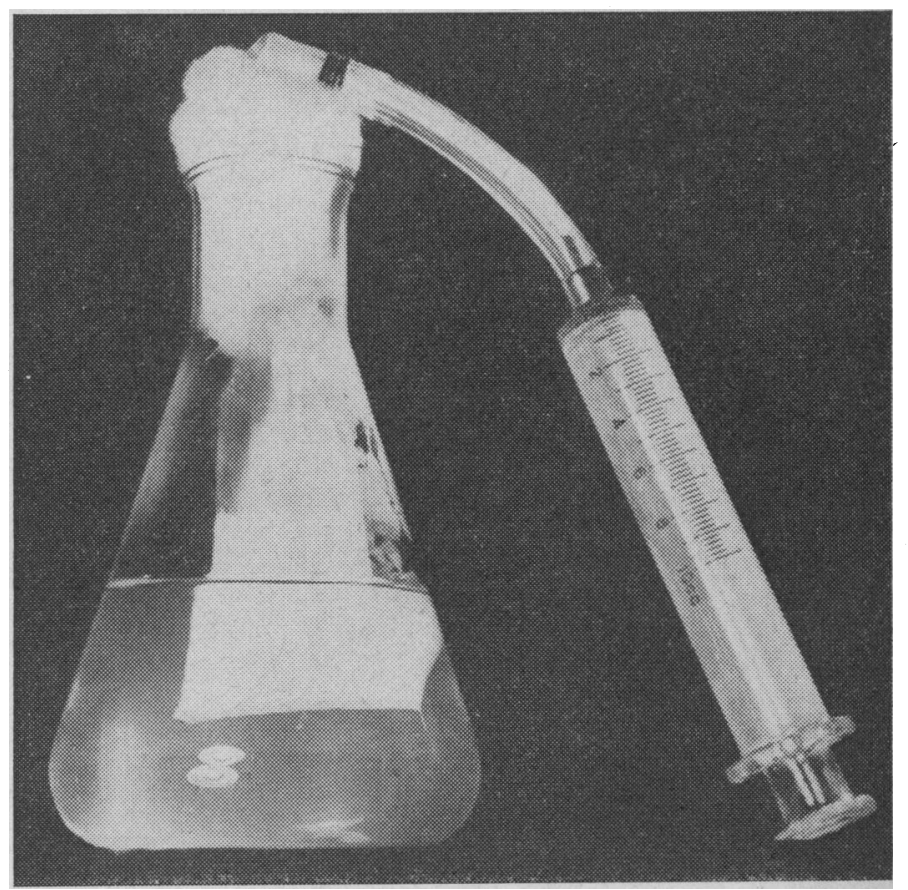

FIG. 2.-Cellophane bag system used for testing the passage of substances across the membrane.

(c) Indole.-Sterile bags containing $10 \mathrm{ml}$. of half-strength peptone water were immersed in 50-ml. cultures of $E$. coli in peptone water which had been incubated at $37^{\circ} \mathrm{C}$. for 24 hours and contained indole. After 5 and 24 hours' immersion a portion of the inside solution was removed and the indole extracted with xylol. The presence of a pink coloration on the addition of the indole reagent was employed to detect indole.

(d) Acetyl-methyl Carbinol.-Cellophane bags containing $10 \mathrm{ml}$. of sterile glucose phosphate peptone water, diluted one in two in water, were immersed in 50-ml. cultures of Aerobacter aerogenes which had been incubated in glucose phosphate peptone water for four days at $37^{\circ} \mathrm{C}$. After 5 and 24 hours a portion of the inside solution was tested for the presence of acetyl-methyl carbinol by the addition of $40 \% \mathrm{KOH}$ and creatine.

(e) Chlorhexidine.-Bags containing $20 \mathrm{ml}$. of brain-heart infusion broth, inoculated with Staph. aureus, were immersed in $200-\mathrm{ml}$. portions of $1 / 200$ chlorhexidine in brain-heart broth. A bag similarly inoculated, immersed in $200 \mathrm{ml}$. of sterile broth without chlorhexidine, served as the control. Each of the above tests was repeated at least three times.

(f) Urease.-A non-sterile preparation of urease was obtained by using tablets each of which was stated by the manufacturers (B.D.H.) to hydrolyse $160 \mathrm{mg}$. of urea in three hours at $15^{\circ} \mathrm{C}$. Two tablets were ground in $20 \mathrm{ml}$. of distilled water. The urease suspension was placed inside a bag which was immersed in $200 \mathrm{ml}$. of a sterile solution containing $100 \mathrm{mg}$. of urea per $100 \mathrm{ml}$. A control was prepared by immersing bags 
containing only distilled water in similar urea solutions. After incubation at $37^{\circ}$ C. for 24 hours the urea in the outside solutions was estimated.

\section{Results}

(a) Pyocyanin was detected on the other side of the membrane after four hours' incubation.

(b) When Staph. aureus toxin was diluted one in two the outside solution did not haemolyse rabbit red cells, but undiluted toxin appeared to pass across the membrane, since the outside solution from this latter test caused haemolysis in 18 hours at $37^{\circ} \mathrm{C}$.

$(c, d)$ Both indole and acetyl-methyl carbinol passed across the membrane in five hours.

(e) When chlorhexidine was present in the outside solution the inside culture remained sterile although it had been inoculated with Staph. aureus. The control system contained $10^{8}$ organisms per $\mathrm{ml}$. in the inside bag.

(f) Urease.-There was a $50 \%$ reduction in the urea concentration after 24 hours' incubation. The controls showed no such reduction.

\section{Discussion}

Since the dialysing fluid is a synthetic medium of similar composition to plasma it is not surprising that bacteria with less fastidious growth requirements have been found in the dialysing fluid. Sherris et al. (1961) have reported a similar problem with contamination by Pseudomonas and Aerobacter species. The dialysing bath itself and perhaps the less accessible pumps and connecting tubing were found to be the chief source of contamination in this present investigation and that of Sherris et al. (1961).

However, in contrast to the findings of Scribner and Caner (1960), and Sherris et al. (1961) there were no instances of transient bacteraemia caused by the bacteria found in the dialysing fluid. Since wet cellophane has a pore radius of 2.5 $\mathbf{m} \mu$, similar to that of the capillaries in the glomerular membrane, formed elements of the blood, plasma proteins, proteinbound substances, and bacteria are not expected to pass across the intact membrane (Marshall, 1961).

The study of the effect of the bacteria on the composition has shown that estimations of urea in the dialysis bath after use would not be an accurate guide to the total amount of urea removed. However, the progress of a dialysis is usually followed by an assessment of urea in the blood and not by the urea values of the dialysis fluid. In this investigation the organisms found in our dialysing bath were used ; other organisms could yield different results. Scribner et al. (1960) attributed the reduction of bicarbonate to zero during one dialysis to bacterial contamination. With the exception of the one instance quoted in the results there was no other evidence of alteration of the ionic concentrations.

Although the bacteria themselves are unable to pass across the cellophane membrane the metabolism of the bacteria may result in the production of smaller toxic molecules which may reach the patient's blood-stream. However, no clinical symptoms could be attributable to such a hypothesis. For this reason an in vitro system was established in an attempt to investigate this theory.

The size of the molecule is of major importance in determining which substances will pass across the membrane. Enzymes and endotoxin molecules are large in comparison with most of the substances tested but small in comparison with a red blood cell, which is the criterion of integrity of the cellophane. The substances selected for testing were of varying molecular weights, but it was not the purpose of this study to determine the size of molecules which may pass across the membrane. A more detailed analysis of the actual presence of bacterial products in the bath while in use and the possible passage of these substances into the patient, although desirable, was not possible.

With the artificial test system it was shown that some bacterial products may pass across the membrane, and, although most of these would not be present in a culture of Ps. pyocyanea, E. coli, Achromobacter sp., or Ps. stutzeri in a medium with the composition of the dialysing fluid, these findings are thought to represent the potential danger of contaminants to a patient. Endotoxins of Gram-negative bacteria particularly come to mind but were not studied because of technical difficulties in detecting them.

When the dialysing fluid is heavily contaminated with bacteria, and in particular Ps. pyocyanea towards the end of a dialysis, there is considerable aerial contamination. It is important to realize the potential pathogenicity of these organisms, especially when one remembers how readily these may be spread through a ward. Moreover, the strains of Ps. pyocyanea and Ps. stutzeri which we encountered were resistant to penicillin, tetracyclines, chloramphenicol, nitrofurantoin, and kanamycin but sensitive to streptomycin. However, with the single exception of a Ps. stutzeri infection in a wound after haemodialysis, there was no clinical evidence of infection in any other patients after haemodialysis by these particular organisms.

From the above evidence it is considered necessary to eradicate this source of contamination of the patient. A study of the problem is being made in this department, and at the present time the use of chlorhexidine after each dialysis has proved to be the most effective method of disinfection, the bath fluid remaining virtually sterile during the next dialysis. The technique used has been to add 6-8 litres of $1 / 250$ dilution of chlorhexidine at $50-60^{\circ} \mathrm{C}$. to the emptied tank for half an hour after each dialysis. This results in immersion of the pumps and tubing but the main tank is only moistened with the solution.

However, this is not thought to be the final answer to this problem. By nature of the composition of the fluid and the size of the container it would be necessary to have a continuous sterilizing procedure operating throughout the dialysis to maintain sterility of the fluid. At the present time the potential hazard of this 100 litres of bacterial culture should be realized and a disinfection procedure such as the one described above should be used.

\section{Summary and Conclusions}

The dialysing fluid of the twin-coil artificial kidney was found to be heavily contaminated with bacteria.

These bacteria were not detected in the blood of patients dialysed against the contaminated solution.

The growth of the bacteria was shown to be associated with a reduction in the urea and glucose concentration.

Pyocyanin, indole, acetyl-methyl carbinol, Staph. aureus haemolysin, urease, and chlorhexidine were shown in vitro to pass across the cellophane membrane used in the artificial kidney.

Such contamination is of potential danger to the patient and should be eradicated. At the present time no completely satisfactory method is available.

\section{REFERENCES}

Marshall, V. (1961). Med. F. Aust., 1, 33.

Miles, A. A., Misra, S. S., and Irwin, J. A. (1938). f. Hyg. (Camb.), 38, 732 .

Scribner, B. H., Buri, R., Caner, J. E. Z., Hegstrom, R., and Burnell, J. M. (1960). Trans. Amer. Soc. artif., intern. Organs, 6, 118. J. C. (1960). Clin. Res., 8, 136.

Sherris, J. C., Cole, J. J., and Scribner, B. H. (1961). Trans. Amer. Soc. artif. intern. Organs, 7, 37. 